\title{
Pulmonary embolism in the COVID-19 pandemic era: Importance of bedside electrocardiography, echocardiography and use of Tenecteplase.
}

\author{
${ }^{*}$ Nwako O.F. ${ }^{1}$, Nwako C.A. ${ }^{2}$, Nwako C.N. ${ }^{3}$, Nwako A.B. ${ }^{4}$
}

\begin{abstract}
Pulmonary embolism is a blockage in one of the pulmonary arteries in the lungs. Globally, it is the third most frequent acute cardiovascular syndrome behind myocardial infarction and stroke. This is a 43-yearold Nigerian diabetic man who had liposuction three weeks before presenting with sudden onset breathlessness, productive cough, chest pain, fever, inability to complete a sentence and inability to carry out his normal daily activities during this coronavirus 2019 (COVID-19) pandemic. He was tachypneic, tachycardic, hypotensive with rapidly dropping oxygen saturation $(84 \%-86 \%, 80 \%-84 \%)$. This presented a diagnostic challenge which was rapidly resolved with bedside electrocardiography and echocardiography. A diagnosis of pulmonary embolism was sustained. Subsequent SARS-COV-2 PCRbased test was negative. He was successfully managed with an antithrombotic agent, tenecteplase, without any adverse events.
\end{abstract}

Keywords: COVID-19, pulmonary embolism, tenecteplase, electrocardiography, echocardiography

\author{
*Corresponding author \\ Nwako O.F. \\ ORCID-NO: http://orcid.org/0000-0001-5402-9552 \\ Email: freeokey@yahoo.com
}

${ }^{I}$ Consultant Physician/ Cardiologist, Head of Accident and Emergency, Department of Internal Medicine, Federal Medical Centre Owerri Nigeria.

${ }^{2}$ Medical Biochemist, Head of Research and Development Unit, Pure Heart and Body Medical Services Owerri, Nigeria.

${ }^{3}$ Head, Drug Information Unit, Department of Pharmacy, Federal Medical Centre Owerri Nigeria.

${ }^{4}$ Consultant Paediatrician, Department of Paediatrics, Queen Elizabeth II Hospital Maseru Lesotho. 


\title{
Embolie pulmonaire à l'ère de la pandémie de COVID-19 : Importance de l'électrocardiographie, de l'échocardiographie et de l'utilisation de Tenecteplase au chevet du patient
}

\author{
*Nwako O.F. ${ }^{1}$, Nwako C.A. ${ }^{2}$, Nwako C.N. ${ }^{3}$, Nwako A.B. ${ }^{4}$
}

\begin{abstract}
Résumé
L'embolie pulmonaire est un blocage dans l'une des artères pulmonaires des poumons. Au niveau mondial, c'est le troisième syndrome cardiovasculaire aigu le plus fréquent derrière l'infarctus du myocarde et l'accident vasculaire cérébral. Il s'agit d'un homme diabétique Nigérian de 43 ans qui a subi une liposuccion trois semaines avant de se présenter avec un essoufflement d'apparition soudaine, une toux productive, des douleurs thoraciques, de la fièvre, une incapacité à terminer une phrase et une incapacité à mener à bien ses activités quotidiennes normales pendant cette pandémie (COVID-19). Il était tachypnéique, tachycardique, hypotendu avec une saturation en oxygène en chute rapide $(84 \%-86 \%$, 80\%-84\%). Ceci a présenté un défi diagnostique qui a été rapidement résolu avec l'électrocardiographie et l'échocardiographie de chevet. Le diagnostic d'embolie pulmonaire a été retenu. Le test ultérieur basé sur la PCR SARS-COV-2 était négatif. Il a été traité avec succès avec un agent anti thrombotique, le tenecteplase, sans aucun événement indésirable.
\end{abstract}

Mots-clés : COVID-19, embolie pulmonaire, tenecteplase, électrocardiographie, échocardiographie

*Corresponding author

Nwako O.F.

ORCID-NO: http://orcid.org/0000-0001-54.02-9552

Email: freeokey@yahoo.com

${ }^{I}$ Consultant Physician/ Cardiologist, Head of Accident and Emergency, Department of Internal Medicine, Federal Medical Centre Owerri Nigeria.

${ }^{2}$ Medical Biochemist, Head of Research and Development Unit, Pure Heart and Body Medical Services Owerri, Nigeria.

${ }^{3}$ Head, Drug Information Unit, Department of Pharmacy, Federal Medical Centre Owerri Nigeria.

${ }^{4}$ Consultant Paediatrician, Department of Paediatrics, Queen Elizabeth II Hospital Maseru Lesotho. 


\section{INTRODUCTION}

The similarities between the clinical presentations of acute pulmonary embolism (PE) and COVID-19, and the documented acute pulmonary embolism among COVID-19 patients warrants prompt detection of the former among patients presenting with shortness of breath, cough, fever and $\mathrm{SPO}_{2}<92 \%$ during this pandemic era. High index of clinical suspicion and the use of available and affordable bedside tools like electrocardiography (ECG) and echocardiography (ECHO) could form the first work-up procedure for early diagnosis of this lifethreatening condition.

We report a case of acute pulmonary embolism in a haemodynamically stable patient on low molecular weight heparin (clexane) but later became unstable, warranting the use of thrombolytic agent, tenecteplase. Because of his presenting clinical features during this pandemic, he was labeled COVID-19 suspect and did not receive adequate care in three facilities due to initial scare. However, he tested PCR negative for COVID-19. Bedside ECG and ECHO with high index of clinical suspicion significantly suggested $\mathrm{PE}$ and aided prompt treatment.

\section{Case Presentation}

K.I, is a 43-year-old Nigerian diabetic man who presented at the emergency during the COVID-19 pandemic with sudden onset of breathlessness and chest pain of two days. He was well until this presentation which started suddenly in the early hours of the day as he woke up. Chest pain was located at the precordium, heavy with no radiations, not position-dependent, no known relieving and exacerbating factor. $\mathrm{He}$ had no known history of contact with individuals with SARS-COV-2 infection and claimed adherence to COVID-19 infection preventive protocols. There were associated histories of cough productive of sputum, fever, anorexia, fatigue, inability to complete a sentence and to carry out activities of normal daily living. He is not a known hypertensive, does not use tobacco in any form, nil history of long travel ( $>$ 6hours), but had liposuction surgery three weeks prior to the onset of illness. He had visited three hospitals that referred him out due to COVID-19 scare.

He was found to be obese with body mass index (BM1) of $36 \mathrm{~kg} / \mathrm{m}^{2}$, restless, febrile $\left(38.2^{\circ} \mathrm{C}\right)$, cyanotic, moderately dehydrated and desaturated $\left(\mathrm{SPO}_{2}: 84 \%-86 \%\right)$. He was also tachypneic (RR-32cpm), tachycardic (106bpm) with a blood pressure (BP) of 100/60 $\mathrm{mmHg}$ and had bibasal coarse crackles. A working diagnosis of acute pulmonary embolism to rule out COVID- 19 was tentatively made. D-Dimer, Cardiac Troponin-T and urgent bedside ECG and echocardiography was requested. Electrocardiogram showed sinus tachycardia, right ventricular hypertrophy, right axis deviation and S1Q3T3 (fig.1). Echocardiogram (fig.2) showed the 60'60 sign. D- Dimer was $0.7 \mathrm{mg} / 1$, random blood glucose was $205 \mathrm{mg} / \mathrm{dl}$, Troponin$\mathrm{T}$ was negative and polymerase chain reaction (PCR) test for COVID-19 was negative (fig.4). A probable diagnosis of acute pulmonary embolism was later made. CT pulmonary angiogram (CTPA) was not done because patient was unstable to be moved more than 4 hours to a centre with the facility.

Patient was placed on subcutaneous clexane at $80 \mathrm{mg}$ a.m and $40 \mathrm{mg}$ p.m, intranasal oxygen at $6 \mathrm{~L} / \mathrm{min}$ via nasal prong, IV meropenem $1 \mathrm{~g} 12$ hourly, azithromycin $500 \mathrm{mg}$ O.D, rosuvastatin $20 \mathrm{mg}$ nocte, IV paracetamol $600 \mathrm{mg}$ 12 hourly, IVF normal saline 12 hourly, subcutaneous soluble insulin at 6i.u 8hourly and was placed on thromboembolic decompression (TED) stockings. Patient was then monitored for clinical progress/deterioration with fluctuating vital signs. Barely 28 hours post admission, his vital signs started deteriorating with an $\mathrm{SPO}_{2}$ of $80 \%-84 \%, \mathrm{BP}=90 / 56 \mathrm{mmHg}, \mathrm{RR}=36 \mathrm{cpm}$ and $\mathrm{PR}=110 \mathrm{bpm}$. At this point the diagnosis was changed to acute submassive pulmonary embolism in imminent circulatory collapse. An urgent decision was made to thrombolyse with IV tenecteplase $50 \mathrm{mg}$ over 5 seconds as a rescue therapy, with close monitoring but no adverse events were recorded. He recorded tremendous steady clinical positive progress in his vital signs and on ECG monitoring (fig.3). He was discharged 72 hours post thrombolysis at an $\mathrm{SPO}_{2}$ of $96 \%-98 \%$ on room air, $\mathrm{BP}=110 / 70 \mathrm{mmHg}$, pulse rate $(\mathrm{PR})=88 \mathrm{bpm}$, respiratory rate $(\mathrm{RR})$ $=22 \mathrm{cpm}$. He was placed on tablet dabigatran $150 \mathrm{mg} \mathrm{BD}$, and to see by one week. On follow up visit, patient was clinically stable with nil complaints and dabigatran was reduced to $150 \mathrm{mg}$ daily for one month.

\section{DISCUSSION}

Venous thromboembolism (VTE) presents as the commonest complication among inpatients in high income countries (1). It has an inpatient incidence of $0.1 \%$ in Nigeria (2). The inhospital case fatality of massive PE is $30 \%, 10$ fold higher than for patients with submassive PE (3). Pro coagulant events especially pulmonary embolism has been reported among COVID-19 
patients (4) and distinguishing their clinical features poses a diagnostic challenge in acute phase especially during this pandemic (5). High index of suspicion is therefore imperative as sign and symptoms are nonspecific.

We decided to report this case due to the general fear of getting infected with COVID-19 and of attending to patients who present with sudden shortness of breath, cough, fever, and perhaps oxygen desaturation without adequate consideration for possible differentials. Hence, this patient failed to receive adequate care in three facilities because of COVID-19 scare.

For adequate management of cases and prognostication, patients with $\mathrm{PE}$ have been categorized into four groups viz: acute massive $\mathrm{PE}$, acute submassive PE, acute PE with pulmonary infarction and acute $\mathrm{PE}$ without pulmonary infarction.

Patients who fall into massive PE often present with signs of haemodynamic instability (systemic hypotension, cold and clammy extremities, tachycardia and tachypnea). They may also appear weak, pale, diaphoretic and develop cognitive impairment. Signs of pulmonary hypertension including loud $\mathrm{P} 2$, right ventricular S3 gallop and palpable impulse over the $2^{\text {nd }}$ left intercostal space may be seen. Among the submassive PE population as in our patient, they may have other symptoms and signs of above but are not haemodynamically unstable. Acute pleuritic chest pain, breathlessness and haemoptysis are seen among those with PE and pulmonary infarction. Also, decreased movement of the involved hemithorax, audible friction rub, local tenderness and a normal ECG are not uncommon. Acute PE without pulmonary infarction have non-specific signs while those with multiple PE or thrombi have signs of pulmonary hypertension or cor pulmonale. Common symptoms of PE including dyspnea, fever, pleuritic chest pain and cough were seen in our patient, although he had no haemoptysis (6). The condition is not without complication and may be a cause of sudden cardiac death, obstructive shock, pulseless electrical activity, arrhythmias and cor pulmonale, which were not observed in our patient. Guidelines have suggested the use of validated clinical scoring system before testing (7). These scoring systems help in determining which level of testing is appropriate and includes Wells rule, simplified Wells rule, revised Geneva score and simplified Geneva score (8). Although our patient had an intermediate clinical probability score using the simplified version of the revised Geneva score, however, his overall clinical status was fast deteriorating. In suspected high-risk $\mathrm{PE}$, as indicated by the presence of haemodynamic instability, bedside echocardiography or emergency CTPA (depending on availability and clinical circumstances) is required for diagnosis (9).

In low- moderate pretest probability, Ddimer testing is recommended as the next step since it has a high negative predictive value (7). The index patient had a positive test for $\mathrm{D}$-dimer quantitative ELISA test which further supported the diagnosis of pulmonary embolism. Bedside investigations including ECG and echocardiography are useful when clinical suspicion of PE is high and has been included in some guidelines for massive PE diagnosis (10). Electrocardiogram could be normal or show sinus tachycardia and non-specific ST-T wave changes as common findings. Other findings include right axis deviation, P-pulmonale, right bundle branch block (RBBB) and the McGinnWhite sign (S1Q3T3). Our patient had sinus tachycardia, P-pulmonale, RBBB, and S1Q3T3 which are usually seen in more severe cases (11) as shown in figure 1. Echocardiography may reveal features of right ventricular $(\mathrm{RV})$ pressure overload and may include: enlarged RV, dilated RV with basal RVEDD/LVEDD $<1.0$, McConnell sign, flattened interventricular septum (IVS) at short axis view, distended inferior vena cava with diminished inspiratory collapse, 60/60 sign, decreased tricuspid annular plane systolic excursion (TAPSE) $<17 \mathrm{~mm}$ and decreased $S^{\prime}<9.5 \mathrm{~cm} / \mathrm{s}$ of tricuspid annulus. Our patient had some of these features including the $60 / 60$ sign, dilated RV with basal RVEDD/LVEDD $<1.0$ and decreased TAPSE. However, in a haemodynamically compromised patient with suspected PE, unequivocal signs of RV pressure overload as already listed, justify emergency reperfusion treatment for $\mathrm{PE}$ if immediate CT angiography is not feasible in a patient with high clinical probability and no other available causes for RV pressure overload (12). Although our patient had an intermediate clinical score, his fast deteriorating clinical state despite optimal anticoagulant therapy and the presence of RV pressure overload, warranted the use of a thrombolytic like tenecteplase as a rescue therapy. This decision was observed to have changed the overall clinical dynamics of this patient and has been given class IB recommendation by the European Society for Cardiology 2019 (13). Computed tomography pulmonary angiography (CTPA) is the imaging 
modality of choice in patients with suspected PE, but our patient could not have this done because of his clinical instability and most importantly the unavailability in our environment. In this test, central filling defect within a distended lumen is a hallmark feature of acute PE (14).

Use of adequate anticoagulation like low molecular weight heparin (LMWH), unfractionated heparin, vitamin $\mathrm{K}$ antagonists and the new oral anticoagulants has remained a cornerstone for treatment of PE. In haemodynamically unstable patients, use of thrombolytic therapy is warranted to reduce the risk of death (15). Our patient had a very high mortality risk (class $\mathrm{V}$ ) using the original version of the Pulmonary Embolism Severity Index (PESI) (16). Although tenecteplase is not licensed by food and drug administration (FDA), USA for pulmonary embolism treatment, we used it as our thrombolytic agent since some studies show remarkable success (17). The use of thrombolytic agents must be balanced against risk-benefit ratio as it is associated with $6 \%$ risk of major bleeding and up to $3 \%$ risk of intracranial haemorrhage, although we did not record any adverse event of bleeding. Other treatment modalities for PE include catheterdirected thrombolysis and surgical embolectomy.

\section{CONCLUSION}

Suspicion of pulmonary embolism (PE) should be high in the differential diagnosis of patient presenting with acute symptoms of breathlessness, cough, fever, weakness and oxygen desaturation $\left(\mathrm{SPO}_{2}<92 \%\right)$ in this COVID-19 era. Bedside investigations including electrocardiography and echocardiography should be undertaken in the emergency room to aid in the early diagnosis and treatment decision of such patients. In intermediate risk suspected PE patients who are clinically deteriorating despite optimal anticoagulant treatment, rescue thrombolytic therapy with tenecteplase may be warranted.

Acknowledgements: We acknowledge the patient with this case.

Competing interests: The authors declare no competing interest. No financial support was obtained from any individual/ organization.

\section{REFERENCES}

1. Beckman MG, Hooper WC, Critchley SE, Ortel TL. Venous thromboembolism: a public health concern. Am. J. Prev. Med. 2010 Apr
1;38(4):S495-501.

2. Elegbeleye OO, Femi-Pearse D. Pulmonary embolism in Africans. Trop. geogr. med. 1975 Mar 1;27(1):31-3.

3. Casazza F, Becattini C, Bongarzoni A, Cuccia C, Roncon L, Favretto G, et al. Clinical features and short term outcomes of patients with acute pulmonary embolism. The Italian Pulmonary Embolism Registry (IPER). Thromb Res. 2012 Dec 1;130(6):847-52.

4. Bompard F, Monnier H, Saab I, Tordjman M, Abdoul H, Fournier L, et al. Pulmonary embolism in patients with COVID-19 pneumonia. Eur. Respir. J. 2020 Jul 1;56(1).

5. Saleh JA, Alasia DD. Acute pulmonary embolism: a review. Niger J Med. 2007 Aug 16;16(1):11-7.

6. Worsley DF, Alavi A. Comprehensive analysis of the results of the PIOPED study. J. Nucl. Med. 1995 Dec 1;36(12):2380-7.

7. Tapson VF. Acute pulmonary embolism. N. Engl. J. Med. 2008 Mar 6;358(10):1037-52.

8. Mos CM, Douma R, Erkens PM, Nizet TA, Durian MF, Hovens MM, et al. Performance of four clinical decision rules in the diagnostic management of acute pulmonary embolism; the prometheus diagnostic accuracy study. Ann. Med. 2011 June 7; 154(11): 709-18

9. Kucher N, Luder CM, Dornhofer T, Windecker S, Meier B, Hess OM. Novel management strategy for patients with suspected pulmonary embolism. Eur Heart J 2003;24:366-376

10. Vanni S, Polidori G, Vergara R, Pepe G, Nazerian $\mathrm{P}$, Moroni F, et al. Prognostic value of ECG among patients with acute pulmonary embolism and normal blood pressure. Am. J. Med. 2009 Mar 1;122(3):257-64.

11. Shopp JD, Stewart LK, Emmett TW, Kline JA. Findings from 12-lead electrocardiography that predict circulatory shock from pulmonary embolism: systematic review and meta-analysis. Acad Emerg Med 2015;22:1127-1137.

12. Dresden S, Mitchell P, Rahimi L, Leo M, RubinSmith J, Bibi S, White L, Langlois B, Sullivan A, Carmody K. Right ventricular dilatation on bedside echocardiography performed by emergency physicians aids in the diagnosis of pulmonary embolism. Ann Emerg Med 2014;63:16-24

13. Marti C, John G, Konstantinides S, Combescure C, Sanchez O, Lankeit M, Meyer G, Perrier A. Systemic thrombolytic therapy for acute pulmonary embolism: a systematic review and meta-analysis. Eur Heart J 2015;36:605-614

14. Nikolaou K, Thieme S, Sommer W, Johnson T, Reiser MF. Diagnosing pulmonary embolism: new computed tomography applications. Journal of thoracic imaging. 2010 May 1;25(2):151-60.

15. Bikdeli B, Madhavan MV, Jimenez D, Chuich T, Dreyfus I, Driggin E, et al. COVID-19 and thrombotic or thromboembolic disease: implications for prevention, antithrombotic 
therapy, and follow-up: JACC state-of-the-art review. J. Am. Coll. Cardiol. 2020 Jun $16 ; 75(23): 2950-73$.

16. Donze J, Le Gal G, Fine MJ, Roy PM, Sanchez O, Verschuren F, Cornuz J, Meyer G, Perrier A, Righini M, Aujesky D. Prospective validation of the Pulmonary Embolism Severity Index. A clinical prognostic model for pulmonary embolism. Thromb Haemost 2008; 100:943-948.

17. Shukla AN, Thakkar B, Jayaram AA, Madan TH, Gandhi GD. Efficacy and safety of tenecteplase in pulmonary embolism. J Thromb Thrombolysis. 2014 Jul;38(1):24-9. doi: 10.1007/s11239-013-0985-x. PMID: 23975441. 


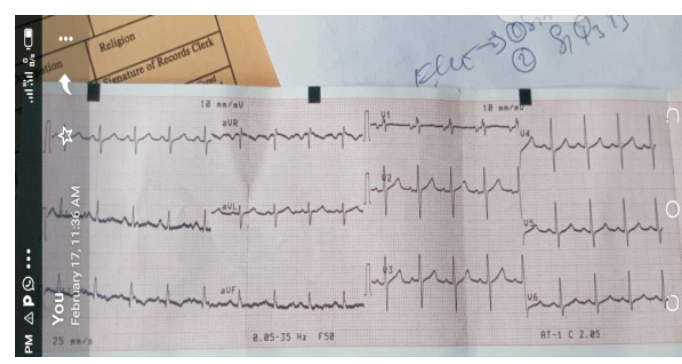

Fig. 1 ECG on presentation showing sinus tachycardia and S1Q3T3

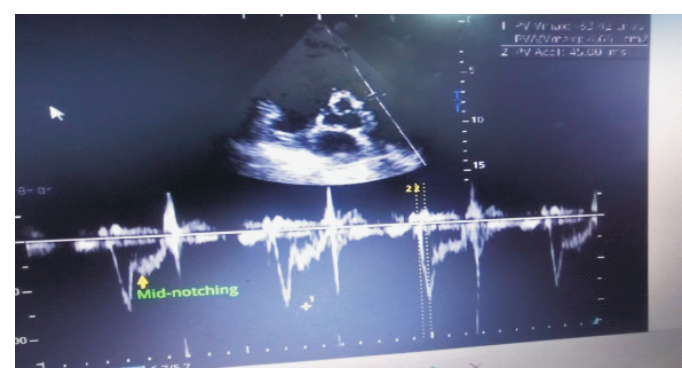

Fig. 2 Echocardiogram on presentation with mid-notching and RVACT: $45.00 \mathrm{~ms}$

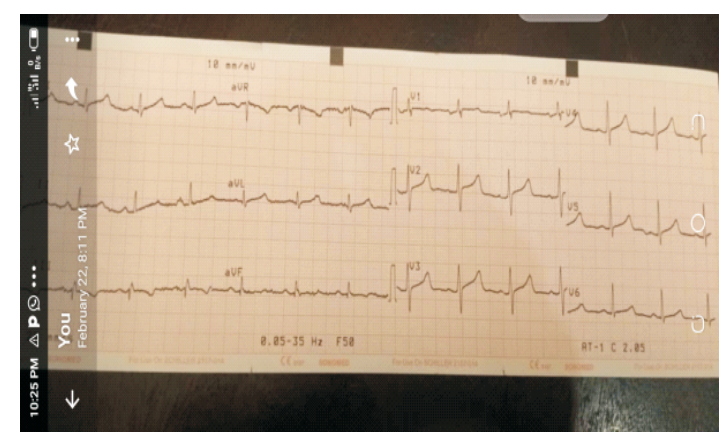

Fig. 3 ECG post treatment showing normal ECG in sinus rhythm

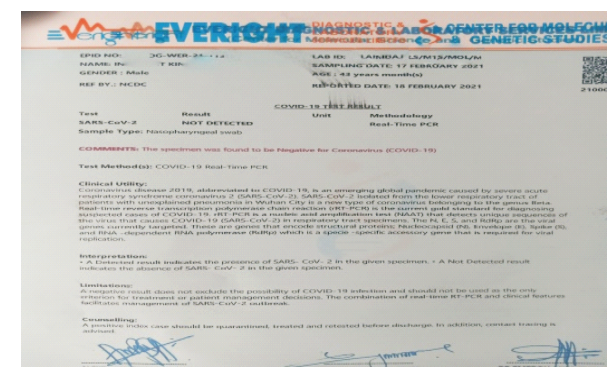

Fig. 4 COVID-19 PCR Negative test 